\title{
Students' Mathematical Critical Thinking Based on Self-Esteem through Problem Based Learning in Geometry
}

\author{
${ }^{1}$ Krida Singgih Kuncoro, ${ }^{2}$ Agustin Zakkia, ${ }^{1}$ Fitria Sulistyowati \& ${ }^{1}$ Betty Kusumaningrum \\ ${ }^{1}$ Mathematics Education, Universitas Sarjanawiyata Tamansiswa, Yogyakarta, Indonesia \\ ${ }^{2}$ SMA Negeri 1 Slawi, Tegal, Indonesia \\ ${ }^{1}$ krida.kuncoro@ustjogja.ac.id
}

\begin{abstract}
This study aims to describe and determine mathematical critical thinking skills based on students' self-esteem. This research used a mixed method with a sequential explanatory research design. The research population was first year mathematics education students who took geometry courses, and the research samples were selected by way of purposive sampling technique. Research subjects were grouped based on high, medium, and low self-esteem categories to be interviewed about students' critical thinking skills. The research instruments were tests and interviews. The results showed that students had various mathematical critical thinking skills in terms of self-esteem. Four students possessed a high level of self-esteem as indicated by the fact that two students' mathematical critical thinking skills results were classified in high category while the remaining two students were in medium category. Of 25 students who had moderate self-esteem, 5 students obtained high category in the results of their mathematical critical thinking skills, 14 students had their result in moderate category students, and 6 students were in the low category. Of 3 students with low self-esteem, one student had their results of the mathematical critical thinking ability result in the high category and two students had their result in the low category. It can be concluded that there is less significant correlation between self-esteem and students' critical thinking skills. Meanwhile, there are three different levels in students' critical thinking skills in terms of self-esteem at high, medium, and low levels.
\end{abstract}

Keywords: mathematical critical thinking, self-esteem, problem-based learning.

\section{Introduction}

In mathematics, prospective teachers or students of mathematics education must have the ability to think logically, analytically, systematically, critically, and creatively to face everevolving life through actions (Bardach \& Klassen, 2020; Hasibuan et al., 2018; Kuncoro et al., 2018; Susilo et al., 2019). Those ability refers to the ability to think at a higher level (Sulistyowati et al., 2019; Widodo et al., 2020) because mathematics is required to think about a problem deductively and inductively and to solve a mathematical problem, not with one solution (Ansori et al., 2020). Mathematical thinking is critical because it can help student to understand the necessity of using knowledge and skills; learning how to learn by oneself and attaining the abilities required for independent learning (Isoda \& Katagiri, 2012).

However, this ideal objective has yet to be fully realized. This is the common problem to mathematics education students at one of the universities in Yogyakarta, especially in geometry. The difficulty in geometry heightens when the materials related to Geometry has to be delivered to elementary, middle, and high school students (Sulistyowati et al., 2017). 
Geometry is one of the compulsory courses for students majoring in Mathematics Education in the first year. The course outcome description of geometry requires students to optimize their thinking abilities, including their critical thinking skills. Critical thinking is an intellectual process that includes applying, analyzing, synthesizing, evaluating information, observing, and reflecting, as a basis for believing and taking actions (Changwong et al., 2018; Md, 2019). Critical thinking is also described as a directed and purposeful thought process (Nappi, 2017). Thus, critical thinking is an activity that is reasoned based on facts and valid arguments as a reference for taking actions or making decisions.

Critical thinking is a reasonable process of reflective thinking that focuses on deciding what to believe or do. According to this definition, critical thinking emphasizes thinking that is reasonable and reflective for use in making decisions (Ennis, 1993). However, given the challenges during the process of making decisions, students often judge themselves as incapable of understanding mathematics. These personal beliefs about skills, abilities, and social relationships are known as self-esteem (Abdel-Khalek, 2016). Self-esteem is a popular and important construct in the social sciences and in everyday life (Blascovich et al., 1991). Students with low self-esteem often cannot see challenges as opportunities but consider them as obstacles. Thus, they will quickly give up before even trying. Self-esteem is self-acceptance by oneself that is related to the feeling of being worthy, valuable, capable and useful (Fennell, 2016). Self-esteem is essential for psychological survival (McKay \& Fanning, 2016). The growing feeling of "I can" and "I am valuable" is the essence of the notion of self-esteem. The effect of self-esteem on students' abilities needs to be analyzed more deeply on its positive impact on the learning process and outcomes.

Many lessons can be used to develop critical thinking skills and self-esteem, one of which is through the problem-based learning model. Problem-based learning model is mathematics learning that uses problem-based learning (Mulyanto et al., 2018). Problem Based Learning is expected to develop and train students' critical thinking skills. Thus, during this learning, students are trained to develop their critical thinking skills.

The purpose of this study was to explore students' critical thinking skills based on selfesteem in solving analytical questions in the plane geometry course through Problem Based Learning using a combined method of sequential explanation design. In the first stage, Problem Based Learning was implemented to measure critical thinking skills. Information from this first stage was further explored in the second qualitative stage. The follow up on qualitative research at the second stage was aimed to better understand and explain students' critical thinking skills based on self-esteem.

\section{Methods}

This research used a mixed method. Data were collected with a sequential explanatory strategy. This strategy was applied by collecting and analyzing quantitative data in the first stage followed by the collection and analysis of qualitative data in the second stage, which was built on the initial quantitative results (Creswell, 2009). This research model is presented in Figure 1. 


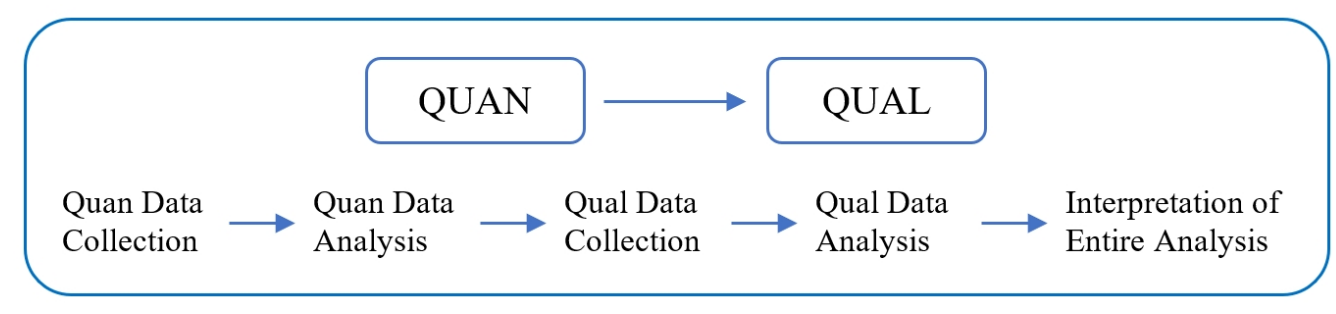

Figure 1. Explanation of mixed methods analysis

The research was conducted at one of the universities in Yogyakarta by involving 32 students taking geometry courses in the first semester 2019/2020 as the research subjects. The research subjects were selected based on a self-esteem questionnaire classified into high, medium, and low groups. Each group consisted of two selected students as research subjects. Out of the total research subjects classified in the high, medium, and low self-esteem group, two students with the highest and lowest questionnaire score were selected in each group. The selection was done to provide an inherent picture on the mathematical critical thinking skills in each self-esteem group.

The research data were derived from the test results of students' critical thinking skills, selfesteem questionnaire results, and interview results of critical thinking skills. Test instruments based on indicators of mathematical thinking skills consisted of five problems to measure interpretation, analysis, evaluation, inference, and explanation (Basri et al., 2019; Fong et al., 2017; Harjo et al., 2019). The indicators of mathematical critical thinking test instruments are presented in Table 1.

Table 1

Indicators of Mathematical Critical Thinking Test

\begin{tabular}{ll}
\hline \multicolumn{1}{c}{ Critical Thinking Indicator } & \multicolumn{1}{c}{ Description } \\
\hline Interpretation & $\begin{array}{l}\text { Students can understand and express the meaning of the given } \\
\text { mathematical statement. }\end{array}$ \\
Analysis & Students can analyze the given mathematical statement. \\
Inference & Students can provide inferences with logical reasons. \\
Evaluation & Students can assess the given claim. \\
Explanation & Students can explain their answer. \\
\hline
\end{tabular}

The critical thinking ability test resulted in quantitative research data, while the answer sheet for students' critical thinking skills, the results of self-esteem questionnaires, and the results of interviews for critical thinking skills generated qualitative data. The quantitative data were tested using the normality test, homogeneity test, proportion completeness test, average completeness test, proportion comparison test, average comparison test, and effective test. Meanwhile, qualitative data were analysed by validating data, making verbal data transcripts, data reduction, data presentation, and data verification.

\section{Results and Discussion}

The quality of learning was measured quantitatively by providing tests of critical thinking skills and mathematical self-esteem. At the learning outcomes stage, it was found that the students' critical thinking test results were normally distributed and homogeneous. The 
calculation of generated the $z_{c} \quad$ value of 2.04. The significance level of $\alpha=5 \%$, and the $z_{(0.4)}$ is 1.64 . Because $2.04 \geq 1.64$, then $z_{C} \quad \leq z_{0.5-\alpha}$, meaning that $H_{0}$ is rejected. Thus, the proportion of class students who obtained learning materials using Problem Based Learning has reached more than $75 \%$ completeness. Based on the calculation results, the $t_{c} \quad$ value is 3.307. The results of the proportion test showed that the proportion of students in Problem Based Learning achieved completeness of more than $75 \%$.

Meanwhile, the Paired Sample T Test revealed that the average critical thinking ability of students after Problem Based Learning is higher than the average critical thinking ability of students before learning Problem Based Learning. This result is denoted by the results of $t_{c}=5.016$ for $\alpha=5 \%$ and $d=31$, while $t_{t_{1}}=1.694$, because $5.016>1.694$ means that $H_{0}$ is rejected and $H_{1}$ is accepted. Therefore, it is conclusive that students have improved their average critical thinking ability after using the Problem Based Learning method. These two aspects indicated the effectiveness of Problem Based Learning provided in the first semester of the geometry course.

The result of regression calculation demonstrated that self-esteem has a positive influence on students' critical thinking skills. Although far from dominance, self-esteem significantly affects students' mathematical critical thinking abilities by $32.2 \%$, while the remaining $67.8 \%$ of students' mathematical critical thinking abilities is influenced by other factors. The results of the analysis on the mathematics self-esteem questionnaire of the students' grouping data are presented in Table 2.

Table 2

Grouping Students based on Mathematical Self-esteem

\begin{tabular}{lll}
\hline Category & The number of students & Percentage \\
\hline High Self-esteem & 4 & $12,5 \%$ \\
Moderate Self-esteem & 25 & $78,1 \%$ \\
Low Self-esteem & 3 & $9,3 \%$ \\
\hline Total & 32 & $100 \%$ \\
\hline
\end{tabular}

From the qualitative data, two students were selected for each self-esteem group as a way to obtain a more comprehensive insight on students' critical thinking skills in each self-esteem group. Subjects at the qualitative stage are presented in Table 3.

Table 3

Subject on Qualitative Stage

\begin{tabular}{lcl}
\hline Category & Subject & Information \\
\hline High Self-esteem & S11 & Highest score in High Self-esteem group \\
& S4 & Lowest score in High Self-esteem group \\
\hline Moderate Self-esteem & S7 & Highest score in Moderate Self-esteem group \\
& S24 & Lowest score in Moderate Self-esteem group \\
\hline Low Self-esteem & S5 & Highest score in Low Self-esteem group \\
& S30 & Lowest score in Low Self-esteem group \\
\hline
\end{tabular}


The followings are some findings on the ability to think critically in mathematics based on self-esteem based on indicators of critical thinking skills, which include Interpretation, Analysis, Inference, Evaluation, and Explanation.

In the High Self-esteem category, S11 scored almost perfect on the critical thinking ability test. The error in the critical thinking ability made by S11 was in the interpretation indicator. The interview results revealed that S11 was less careful in examining the rectangular shape's properties in question. In contrast to S4, apart from the analysis indicator, S4 also made an error on the explanation indicator. During the interview, it was known that S4 made a mistake because he forgot the formula could not focus on understanding the questions.

In the Moderate Self-esteem category there were S7 and S24. S7 made some errors related to three indicators, namely interpretation, inference, and explanation. S7 made a mistake because he did not fully understand the information contained in the questions. S7 was also less precise in providing written evidentiary reasons. On the other hand, S24 only made mistakes on two indicators, namely interpretation, and evaluation.

In the Low Self-esteem category, S5 only made mistakes on questions related to two indicators, namely the interpretation and inference indicators. Meanwhile, S30 made some errors on questions related to four indicators, namely interpretation, analysis, inference, and evaluation. S5 already had an overview on the steps to answer the questions, but he could not explain the reasons in the written answer sheet. S30 made many mistakes because he could not understand the provided questions and was unable to provide reasons for the steps of evidence.

At the qualitative stage, it was clear that self-esteem did not significantly influence critical thinking skills. This result is indicated by the score of S24 and S5. Although S24 was in the Moderate Self-esteem category, and S5 was in the Low Self-esteem category, both only made mistakes on questions related to two indicators.

Most students made errors on questions related to interpretation indicator. The error percentage of almost all research subjects on questions related to interpretation indicator amounted to $84.38 \%$. An example of an error in the interpretation indicator is shown in Figure 2. The figure explained that S7 could not comprehend the problem correctly. The question was about an equilateral triangle, but S7 wrote that the triangle had a different angle. Interpretation is an indicator of the mathematical critical thinking skill and is also an important indicator (Dolapcioglu \& Doğanay, 2020). Most of the mistakes occur because students do not solve the provided problems. Errors in interpretation also occur because students do not understand the concept correctly. Students' inability to understand the keys to the problem results in mistakes in solving the problem (Royce et al., 2019; Shanta \& Wells, 2020; Ulger, 2018). The interview revealed that most mistakes were attributed to students' lack of familiarity with such type of questions. Most students have never encountered similar questions and some students thought that the questions given were too difficult. This fact is in line with the findings that students are unable to interpret the questions well because this is the first time they have encountered a similar question (Basri et al., 2019). 


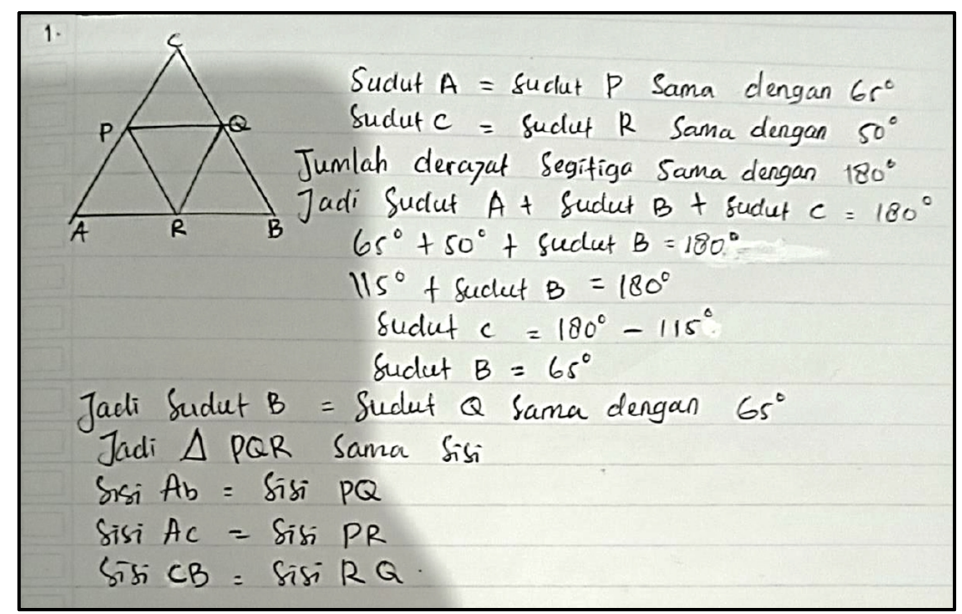

Figure 2. Work result of S7 at interpretation indicator

In the analysis indicator, students have not been able to identify the relationships between the statements expressed. The written calculation strategy is not correct, and the reasons written are also incomplete and incorrect. One example of an analysis error occurred in the work of subject S30. Besides being unable to understand the questions correctly, S30 was also unable to relate the provided mathematical statements, as can be seen in Figure 3. The interviews disclosed that some students were still having difficulty in linking each statement to the provided geometric properties. This finding is in line with a research conducted by Agoestanto and Sukestiyarno (2017), arguing that critical thinking skills are also the ability to think analytically because of an effort, connection, and all aspects of a problem situation, including the ability to gather information, remember, analyze situations, read and understand, and identify necessary things.

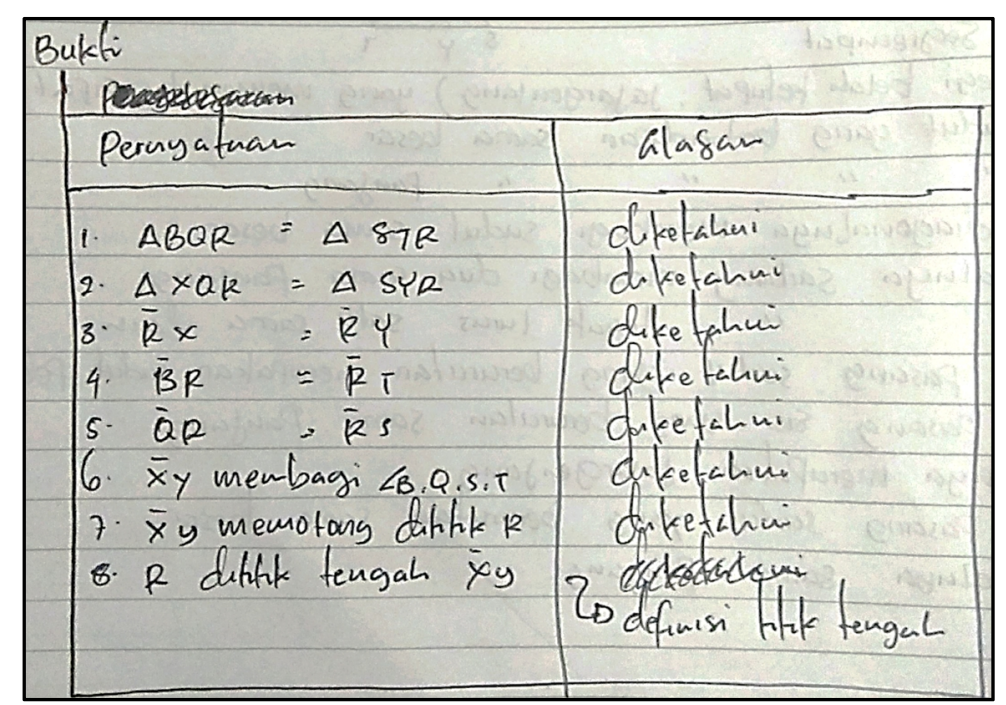

Figure 3. Work result of S30 at interpretation indicator

Inference is a "gathering" of credible, relevant and logical evidence based on previous analysis and evaluation of available evidence, for the purpose of "drawing a reasonable conclusion" (Facione, 2011). In the inference indicator, students have not been able to write conclusions correctly on the completion steps. This is shown in Figure 4, in which subject S5 
could not identify the statement in the question. Subject S5 was supposed to prove that $\bar{A}$ and $\bar{B}$ bisect each other, but instead he used those statements to do the proof. This strategy made S5 unable to find the right conclusion based on the written statement. The interview demonstrated that students did not know how to solve problems, were not careful in observing and understanding the statements given and had problem in formulating conclusions because of less careful calculation of the result even though the previous step was correct. This finding corresponds with the statement that students fail to give the correct inference because they cannot identify the statement given (Basri et al., 2019).

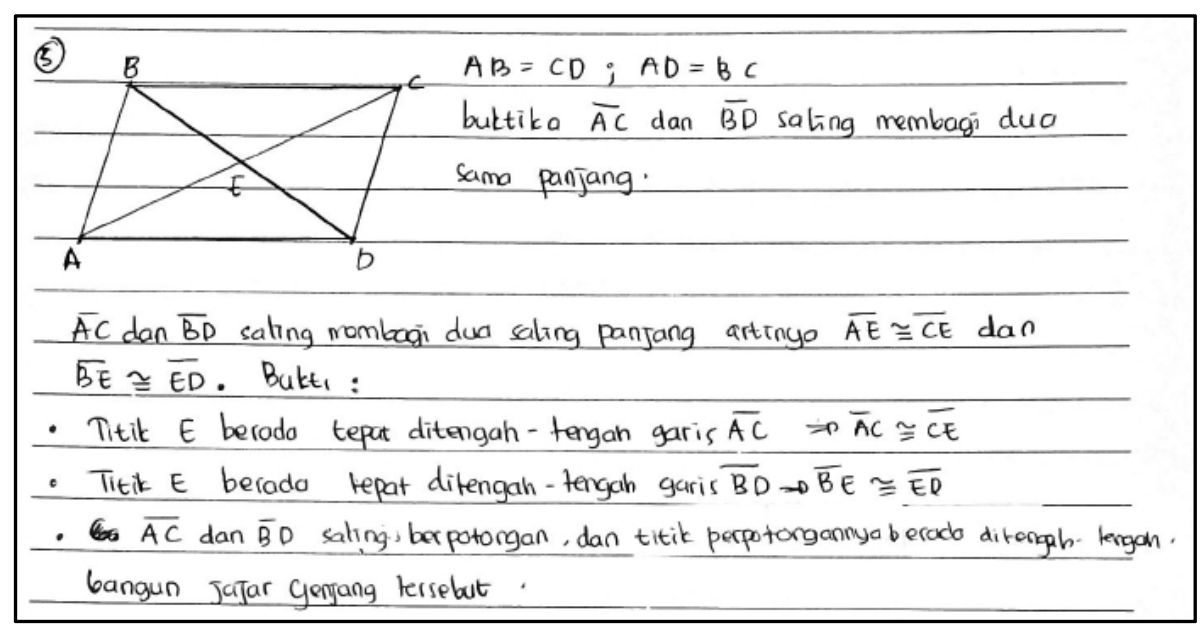

Figure 4. Work result of S5 at inference indicator

Evaluation is a critical thinking sub-skill that is used to determine the overall strength or weakness of an argument (Dwyer et al., 2014). In the evaluation indicator, most of errors occur because students did not provide precise evidentiary reasons in the written answer sheet. This result can be seen from the results of the work of Subject S24 in Figure 5. From the work results, the evidentiary reasons written are still inaccurate. The interviews found that some students were not careful in solving the questions. They also could not find ideas to prove the statement given.

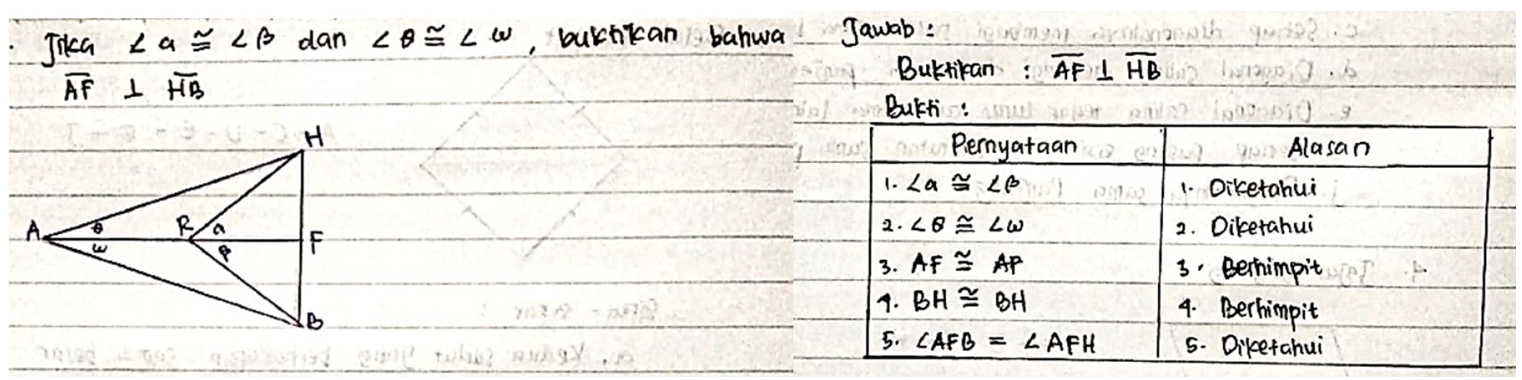

Figure 5. Work result of S24 at evaluation indicator

In the explanation indicator, based on the results of the interview, an error occurred because some students did not understand the material given. Consequently, students were unsure of their answers. A clear example of this case is seen from the work result of S30 in Figure 6. The subject S30 has not been able to build proof based on the concept of congruence, so he could 
not solve the problem. Students' failure to provide good explanations was attributed to students' lack of knowledge of geometric concepts. A good comprehension of the geometry concept is very important to allow students to understand the world by comparing shapes, objects, and their relationships (Jelatu, 2018). This result resembles a research, which stated that the increasing understanding on mathematical critical thinking is in line with students' understanding of the related concepts (Agoestanto \& Sukestiyarno, 2017; Basri et al., 2019).

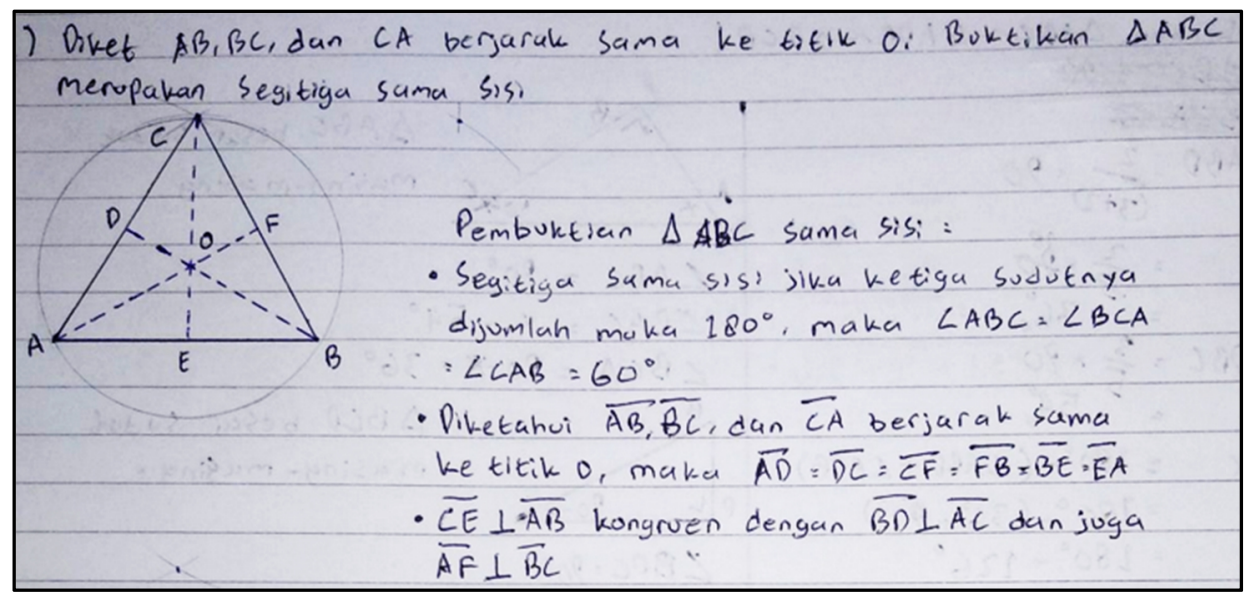

Figure 6. Work result of S30 at explanation indicator

The abovementioned description shows a significant difference in the mastery of critical thinking skills between students in the high mathematics self-esteem category and students in the moderate and low mathematics self-esteem category through Problem Based Learning. Students who have high mathematical self-esteem tend to have higher mathematics critical thinking skills than students with lower mathematics self-esteem. This is in accordance with the opinion of (Schultze-Krumbholz et al., 2018) about low self-esteem, which makes it difficult for students to complete their own tasks. This finding also confirms that self-esteem is an essential concern in learning as expressed by (Ghilay \& Ghilay, 2017) that self-esteem is related to a number of life factors, one of which is student success at school. Thus, self-esteem is essential for every teaching and learning activity at schools. As a result, students with low math self-esteem still need many activities that stimulate their reasoning and conceptual understanding.

\section{Conclusion}

Based on data analysis and discussion on the research results on the role of self-esteem on students 'critical thinking skills through Problem Based Learning, this study has achieved its objectives. Self-esteem has a positive influence on students' critical thinking skills, although not dominant. In other words, it can be concluded that there is a less significant effect between self-esteem and students' critical thinking skills. On the other hand, students' critical thinking skills in terms of self-esteem can be differentiated into three categories: high, moderate, and low levels. From the results of the analysis of the five indicators of critical thinking skills (interpretation, analysis, inference, evaluation, and explanation), the interpretation indicator is the one that generates the highest number of errors based on students' mastery compared to other critical thinking indicators. 


\section{References}

Abdel-Khalek, A. M. (2016). Introduction to the psychology of self-esteem. Self-Esteem: Perspectives, Influences, and Improvement Strategies, 1-17.

Agoestanto, A., \& Sukestiyarno, Y. L. (2017). Analysis of mathematics critical thinking students in junior high school based on cognitive style. Journal of Physics Conference Series, 824(1), 12052. https://doi.org/10.1088/1742-6596/824/1/012052.

Ansori, H., Hidayanto, T., \& Noorbaiti, R. (2020). Critical thinking skill of prospective mathematics teachers in solving the two-dimensional geometry problem. Journal of Physics: Conference Series, 1422(1), 12004. https://doi.org/10.1088/17426596/1422/1/012004.

Bardach, L., \& Klassen, R. M. (2020). Smart teachers, successful students? A systematic review of the literature on teachers' cognitive abilities and teacher effectiveness. Educational Research Review, 30, 100312. https://doi.org/10.1016/j.edurev.2020.100312

Basri, H., Purwanto, As'ari, A. R., \& Sisworo. (2019). Investigating critical thinking skill of junior high school in solving mathematical problem. International Journal of Instruction, 12(3), 745-758. https://doi.org/10.29333/iji.2019.12345a.

Blascovich, J., Tomaka, J., Robinson, J. P., Shaver, P. R., \& Wrightsman, L. S. (1991). Measures of self-esteem. Measures of Personality and Social Psychological Attitudes, 1, 115-160. https://doi.org/10.1016/B978-0-12-590241-0.50008-3.

Changwong, K., Sukkamart, A., \& Sisan, B. (2018). Critical thinking skill development: Analysis of a new learning management model for Thai high schools. Journal of International Studies, 11(2). https://doi.org/10.14254/2071-8330.2018/11-2/3.

Creswell, J. W. (2009). Research design: Qualitative, quantitative, and mixed methods approaches (3rd ed). Research Design Qualitative Quantitative and Mixed Methods Approaches. https://doi.org/10.1016/j.math.2010.09.003.

Dolapcioglu, S., \& Doğanay, A. (2020). Development of critical thinking in mathematics classes via authentic learning: an action research. International Journal of Mathematical Education in Science and Technology, 1-24. https://doi.org/10.1080/0020739X.2020.1819573.

Dwyer, C. P., Hogan, M. J., \& Stewart, I. (2014). An integrated critical thinking framework for the 21st century. Thinking Skills and Creativity, 12, 43-52. https://doi.org/https://doi.org/10.1016/j.tsc.2013.12.004.

Ennis, R. H. (1993). Critical thinking assessment. Theory into Practice, 32(3), 179-186. https://doi.org/10.1080/00405849309543594.

Facione, P. A. (2011). Critical thinking: What it is and why it counts. Insight Assessment, 2007(1), 1-23.

Fennell, M. (2016). Overcoming low self-esteem: A self-help guide using cognitive behavioural 
techniques. Hachette UK.

Fong, C. J., Kim, Y., Davis, C. W., Hoang, T., \& Kim, Y. W. (2017). A meta-analysis on critical thinking and community college student achievement. Thinking Skills and Creativity, 26, 71-83. https://doi.org/https://doi.org/10.1016/j.tsc.2017.06.002

Ghilay, Y., \& Ghilay, R. (2017). ISMS: A new model for 1mproving student motivation and self-esteem in primary education. International Electronic Journal of Elementary Education, 7(3), 383-398.

Harjo, B., Kartowagiran, B., \& Mahmudi, A. (2019). Development of critical thinking skill instruments on mathematical learning high school. International Journal of Instruction, 12(4), 149-166. https://doi.org/https://doi.org/10.29333/iji.2019.12410a

Hasibuan, A. M., Saragih, S., \& Amry, Z. (2018). Development of learning materials based on realistic mathematics education to improve problem solving ability and student learning independence. International Electronic Journal of Mathematics Education. https://doi.org/10.29333/iejme/4000

Isoda, M., \& Katagiri, S. (2012). Mathematical thinking: How to develop it in the classroom (monographs). World Scientific Publishing.

Jelatu, S. (2018). Effect of GeoGebra-aided REACT strategy on understanding of geometry concepts. International Journal of Instruction, 11(4), 325-336. https://doi.org/https://doi.org/10.12973/iji.2018.11421a

Kuncoro, K. S., Junaedi, I., \& Dwijanto, D. (2018). Analysis of problem solving on project based learning with resource based learning approach computer-aided program. Journal of Physics: Conference Series, 983(1), 12150. https://doi.org/10.1088/17426596/983/1/012150

McKay, M., \& Fanning, P. (2016). Self-esteem: A proven program of cognitive techniques for assessing, improving, and maintaining your self-esteem. New Harbinger Publications.

Md, M. R. (2019). 21st century skill "problem solving”: Defining the concept. Asian Journal of Interdisciplinary Research, 2(1), 64-74. https://doi.org/10.34256/ajir1917

Mulyanto, H., Gunarhadi, G., \& Indriayu, M. (2018). The effect of problem based learning model on student mathematics learning outcomes viewed from critical thinking skills. International Journal of Educational Research Review, 3(2), 37-45. https://doi.org/10.24331/ijere.408454

Nappi, J. S. (2017). The importance of questioning in developing critical thinking skills. Delta Kappa Gamma Bulletin, 84(1), 30.

Royce, C. S., Hayes, M. M., \& Schwartzstein, R. M. (2019). Teaching critical thinking: a case for instruction in cognitive biases to reduce diagnostic errors and improve patient safety. Academic Medicine, 94(2), 187-194. https://doi.org/10.1097/ACM.0000000000002518

Schultze-Krumbholz, A., Hess, M., Pfetsch, J., \& Scheithauer, H. (2018). Who is involved in cyberbullying? Latent class analysis of cyberbullying roles and their associations with aggression, self-esteem, and empathy. Cyberpsychology: Journal of Psychosocial 
Research on Cyberspace, 12(4). https://doi.org/10.5817/CP2018-4-2

Shanta, S., \& Wells, J. G. (2020). T/E design based learning: assessing student critical thinking and problem solving abilities. International Journal of Technology and Design Education, 1-19. https://doi.org/10.1007/s10798-020-09608-8

Sulistyowati, F., Budiyono, B., \& Slamet, I. (2017). Problem solving reasoning and problem based instruction in geometry learning. Journal of Physics: Conference Series, 895(1). https://doi.org/10.1088/1742-6596/895/1/012045

Sulistyowati, F., Kuncoro, K. S., Setiana, D. S., \& Purwoko, R. Y. (2019). Solving high order thinking problem with a different way in trigonometry. Journal of Physics: Conference Series, 1315(1), 12001. https://doi.org/10.1088/1742-6596/1315/1/012001

Susilo, B. E., Darhim, D., \& Prabawanto, S. (2019). Students critical thinking skills toward concepts differences in finding area of a plane region and definite integral. Unnes Journal of Mathematics Education, 8(1), 1-7. https://doi.org/10.15294/ujme.v8i1.29463

Ulger, K. (2018). The effect of problem-based learning on the creative thinking and critical thinking disposition of students in visual arts education. Interdisciplinary Journal of Problem-Based Learning, 12(1). https://doi.org/10.7771/1541-5015.1649

Widodo, S. A., Pangesti, A. D., Istiqomah, I., Kuncoro, K. S., \& Arigiyati, T. A. (2020). Thinking process of concrete student in solving two-dimensional problems. Jurnal Pendidikan Matematika, 14(2), 117-128. https://doi.org/10.22342/jpm.14.2.9460.117128 
52 Southeast Asian Mathematics Education Journal, Volume 11, No 1 (2021) 